Journal of Al Azhar University Engineering Sector

Vol. 11, No. 40, July, 2016, 927-942

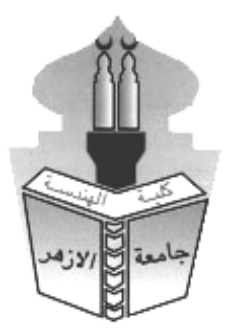

\title{
HIGH-RISE BUILDINGS WITH TRANSFER FLOORS: CONSTRUCTION STAGES ANALYSIS
}

\author{
Yasser M. Abdlebasset ${ }^{1}$, Ezzeldin Y. Sayed-Ahmed ${ }^{2}$, Sherif A. Mourad ${ }^{3}$ \\ ${ }^{1}$ Faculty of Engineering, Cairo, University Cairo University, Egypt \\ ${ }^{2}$ Structural Eng. Dept., Ain Shams University, Egypt, \\ ${ }^{3}$ Structural Engineering Dept., Faculty of Engineering, Cairo, University,
}

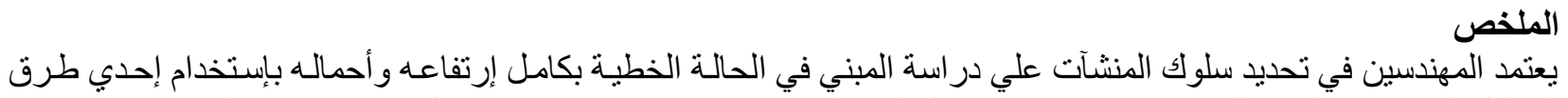

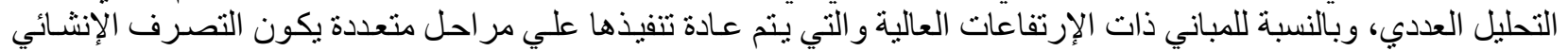

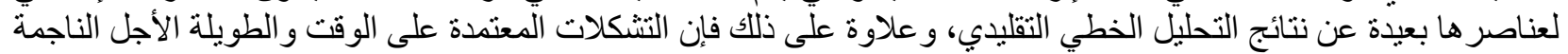

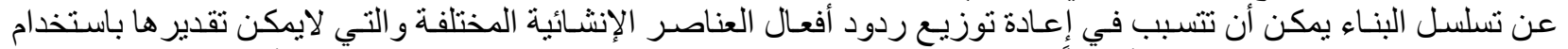
الطرق التقليدية، وكذللك فإن وجود أدوار أ إنتقالية في المبانى العالية يضيف إلى تعقد النظم الإنشـائية التي أيضـا لإئية يمكن تحليلها

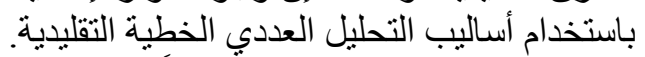

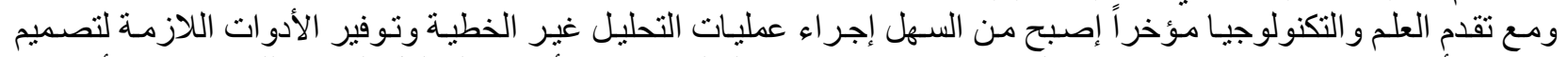

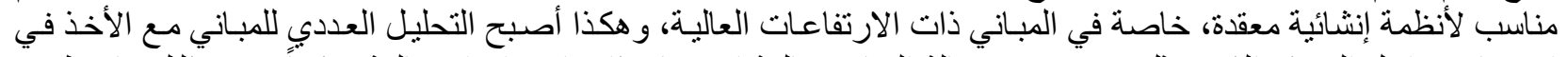

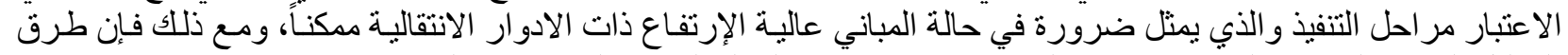

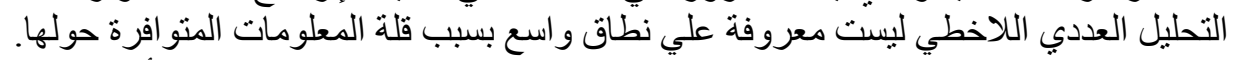

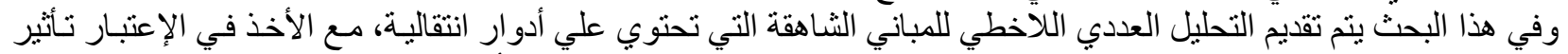

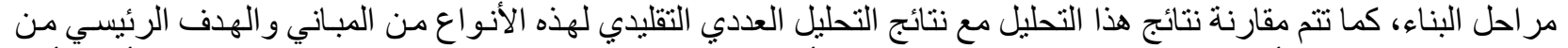

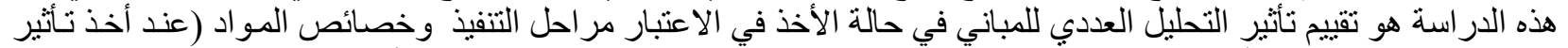
الوقت في الاعتبار) على أداء وتصميم العناصر الإنشائية المختلفة للمباني عالية الارتفاع ذاتية الألئ الأدوار الانتقالية.
\end{abstract}

\begin{abstract}
Engineers generally determine the behavior of structures by adopting a linear elastic numerical analysis including summations of vertical column loads. For high-rise buildings with multiple construction phases, the structural responses may significantly diverge from such a typical linear analysis results. Furthermore, time-dependent long-term deformation resulting from construction sequence can cause a redistribution of the structural responses that cannot be estimated using conventional methods. The existence of a transfer floor within the building height adds to the complexity of the structural system which also cannot be analyzed using typical linear analysis methods. Fortunately, recent advancement of the finite element method facilitated the nonlinear analysis and provided tools for proper design of complex structures, especially high-rise buildings. Thus, construction sequential analysis which is now essential for high-rise buildings with transfer slabs can be easily included in the analysis. However, this nonlinear analysis is not so popular because of lack of knowledge about its necessity and scope. In this research, a nonlinear numerical analysis for high rise buildings with transfer floor is presented, considering the effect of construction stages. The analysis results are compared to the results of a conventional analysis for these types of buildings. The main objective of this work is to assess the effect of construction stages analysis and time dependent material properties of various structural elements for a high-rise building with a transfer floor on the performance and design of these buildings.
\end{abstract}




\section{Key Words: High Rise, Transfer Floor, Construction Stage, Elastic Column Shortening, Creep, Shrinkage.}

\section{INTRODUCTION}

Staged construction is defined as a modeling, analysis, and design application in which structural systems and load patterns are added or removed, and time-dependent behaviors are evaluated; including creep, shrinkage and aging (change in elastic modulus with age). By the predetermined construction processes, building structures are constructed one floor at a time or several floors at a time. Also, within the same construction phase, the construction sequence and loading time could be sometimes different. Therefore, the results of typical structural analysis that simultaneously apply load to a structure could be significantly different from the actual behavior of the structure.

The structural analysis of multi-story buildings is one of the areas that have attracted researchers' attention. In the structural analysis of multistory buildings, the effect of the sequential application of loads due to the sequential construction is an important factor to be considered in the analysis (Figure 1). In fact, the structural members are added to the numerical model in stages similar to the actual construction sequence of the building and, hence, their dead load is carried by that part of the structure completed at the stage of their introduction to the model. Therefore, it is clear that the distribution of displacement and stresses in the a completed part of the structure at any stage due to the dead loads introduced at a certain stage does not depends on sizes, properties, or the presence of members composing the above floors. The correct distribution of the displacements and stresses of any members can be obtained by accumulating the results of analysis of each stage. Ignoring this effect may lead to incorrect results out of the analysis, particularly at the lower floors of the building. Therefore, it is necessary to calculate the load distribution and analyze the structure at every construction stage and to make sure that the loads carried by the supporting components do not exceed their strength and to account for the actual time-dependent effect. However, it is rather difficult to estimate accurately the load distribution in the system because of the time dependent behavior of the building materials and the complexity of construction stages.

Like so many other analyses, construction sequential analysis have specific purposes in design phase of the structures. As mentioned earlier, it deals with behavior under static loads in the form of sequential load increment and its effects on structure considering the structural members are started to react against load prior to completing the whole structure. For the finite element analysis one of the leading analysis software in this arena is MIDAS which is used in the current work to perform the construction stage analysis [1].

\section{Material Time Dependent Effect}

The determination of strains in structures caused by creep and shrinkage is a complex problem. Even though much research has been carried out to determine these effects, the phenomenon of creep and shrinkage still constitutes an interesting research topic and remains to be fully understood. Moreover, creep and shrinkage in concrete structures have not been researched fully by using nonlinear staged construction analysis. Hence, staged analysis and consideration of nonlinear behavior is a main feature of this research.

Creep

Creep is defined as deformation of structure under sustained load. Basically, long term pressure or stress on concrete can make it change shape with time. This deformation usually occurs in the direction of the applied force. Creep does not necessarily cause concrete to fail or break apart. The effect of creep is considered in design by factoring the elastic deformation. There are many factors affecting creep such as aggregate type, mix proportions and age of concrete. Aggregate undergoes very little creep; it is really the cement paste which is responsible for the creep. Age at which a concrete member is loaded will also have a predominant effect on the magnitude of creep. 


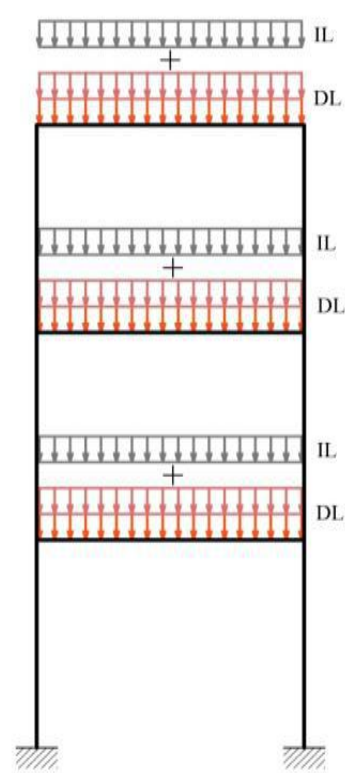

(a)

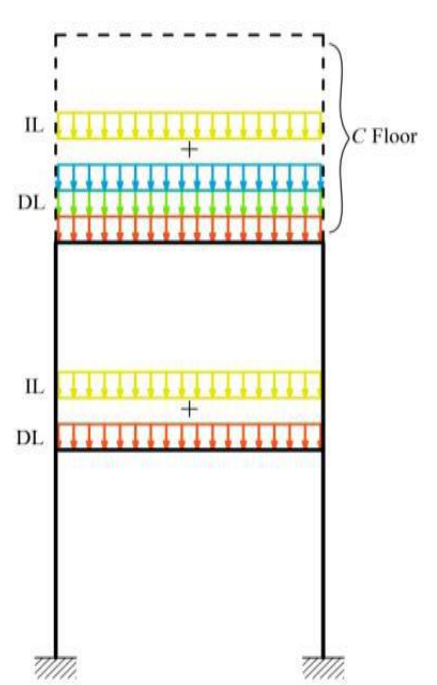

(b)

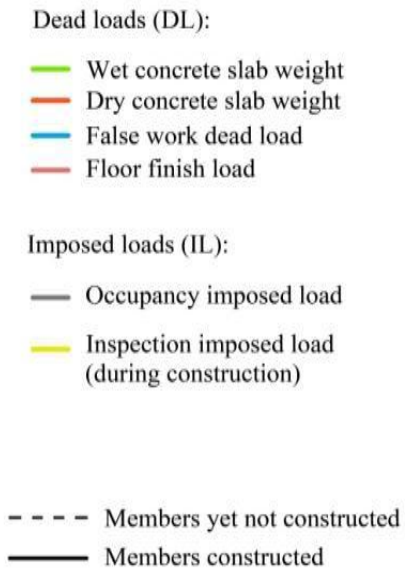

Fig. 1. Loading Breakdown At A) Conventional Analysis; (B) Construction Stage Analysis.

Creep has many effects on concrete; in reinforced concrete beams, creep increases the deflection with time and may be a critical consideration in design. In eccentrically loaded columns; creep increases the deflection and can lead to buckling. In case of statically indeterminate structures and column-to-beam connections creep may relieve the stress concentration induced by shrinkage, temperature changes, or movement of support. However, creep effect must be considered as it changes the distribution of the internal forces for statically indeterminate structures which is typical of all high-rise buildings.

Shrinkage Shrinkage is a time-dependent volumetric change associated with the drying and moisture transfer, thermal effects and gradients, and autogenous behavior (early-age chemical and structural reactions) of restrained reinforce-concrete (RC) systems.

Volume change is one of the most detrimental properties of concrete, mainly because it causes unsightly cracks in concrete. Restraint conditions which affect shrinkage behavior may be external, as with supports, connections, and boundary conditions, or internal, as with differential drying and reinforcement. Shrinkage cracking is mitigated with increased amounts of reinforcement at decreased spacing, and with the inclusion of coarse aggregate which is dense, hard, and less compressible. The proper early-age handling and curing of concrete further mitigates shrinkage while enhancing long-term life expectancy and structural performance.

\section{Effects of shrinkage and creep deflections}

The amount of the absolute deflection from drying shrinkage and creep that advance as the time passes will be twice as large as the amount of flexural deflection. Therefore, in the case of a high-rise building, an error will be generated if the amount of inelastic deflection of the concrete members was ignored (Figure 2). The accurate compensation value and stress can only be calculated by taking into consideration the amount of inelastic deflection and stress redistribution from the frame action of the overall structure, not an independent member.

Creep, along with shrinkage (decrease in direct strains over time) and aging (change in elastic modulus with age), are time-dependent material behaviors which may be applied to concrete objects using staged-construction analysis (Figure 2). Creep and shrinkage behaviors are specified in the MIDAS model according to CEB-FIP parameters [2].

\section{Elastic column shortening}

Elastic column shortening is a secondary effect which needs to be considered in the construction and design of high-rise buildings. During the construction of a building, columns would be subjected to a number of load increments. These load increments vary as the 
sequence of construction varies. Axial shortening of columns in building structures results in differential shortening of them and causes axial force redistribution among columns and walls. Differential shortening may also lead to additional forces in the horizontal members like beams and slabs. For these reasons, construction method and stages should be considered in design as well as at construction of buildings. Elastic deformation of columns is a major contributor to the axial shortening of columns. To take into account the effect of construction sequence, live load should be applied simultaneously and dead load should be applied sequentially in the analysis and design of buildings.

Elastic shortening of columns is cumulative over the height of a structure. As the height of the building increases, the resultant differential shortening becomes an important design criterion which needs to be taken into consideration. Nonlinear components of the axial shortening include inelastic shortening due to creep and shrinkage. Differential axial shortening may cause cracking and deflection of floor plates, beams and other structural components, damage to facades, finishes, claddings mechanical and plumbing components and other masonry walls. It also increases the bending moments and shear forces in framing.

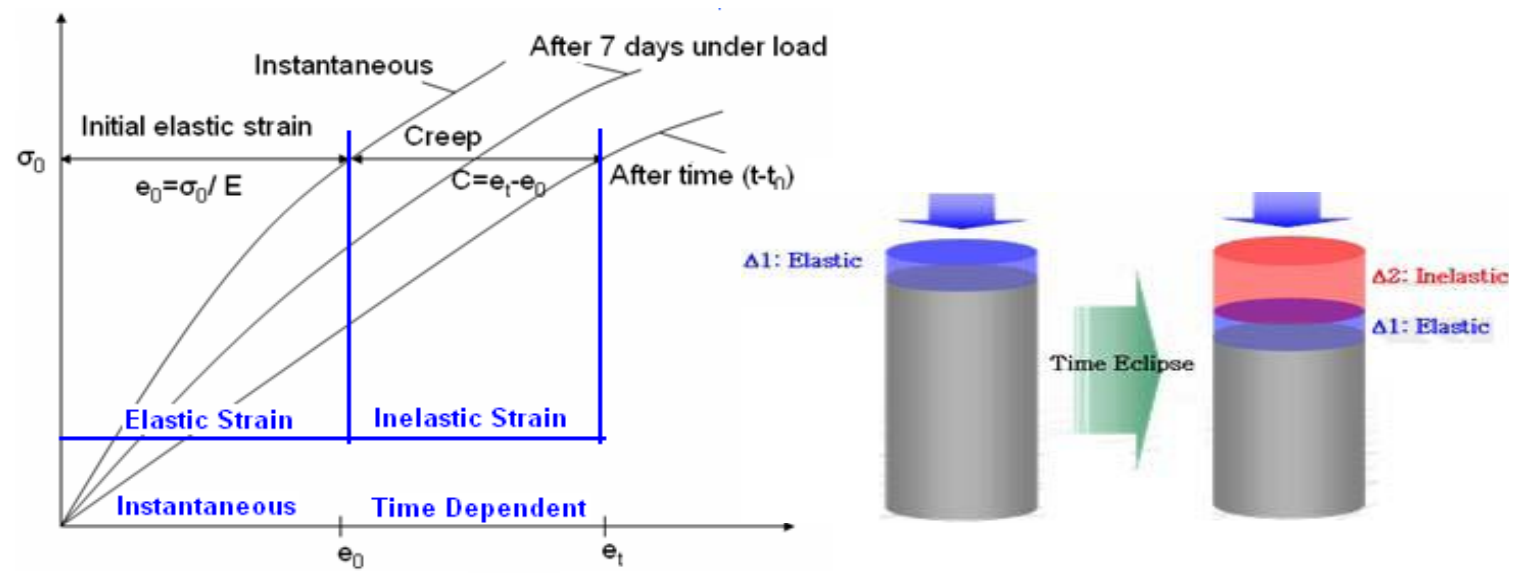

Figure 2: Comparison between elastic and inelastic strain.

In many design practices, however, there is a tendency to design exterior columns having nearly equal cross-sectional areas to the interior ones, mainly because additional cross sections are required in the exterior columns in order to resist the forces induced by the overturning moments due to their lateral loads. Therefore, a substantial inequality exists between ratios of gravity load to the cross-sectional area of exterior columns and that of interior columns. In a high-rise buildings, considerable amounts of differential column shortening is accumulated in the members of the upper stories, and so are bending moments and shear forces when the gravity load analysis for the building is performed by a typical linear numerical analysis of the whole building. These differential column shortening and bending moments due to the dead load may be overestimated because the linear analysis methods which do not take into account the sequential nature of the construction and of the application of building weight (Figure 3).

\section{Analysis Methodology}

The strength, stability and deflection checks in the conventional linear analysis consider the whole structure without accounting for the sequential process. In reality, the behavior of the components or units in the erection process is different from the ideal case because instability and excessive deflection occur in the construction stage with limited propping. Furthermore, shortening and undesirable deformations of the incomplete structure under self-weight and construction loads are inevitable. The structural self-weight, external loads, boundary conditions and materials are depended on the stages followed during the construction process and their variations are overlooked in conventional design.

Grouping of some stories is considered to create a step so that the software can identify the total steps required for completing the procedure. Step by step analysis, considering nonlinear behavior of materials from previous step, ensures that the construction sequence effects are properly represented in the study. Recording and investigating the variation of responses, of a 
particular point from starting step of sequential analysis to the last one, exhibit how construction sequence has a significant impact on the design of the structures. The comparison between the findings of construction sequential analysis and linear analysis highlights the importance of considering sequential effects during design and eventually meet the objectives of this study.

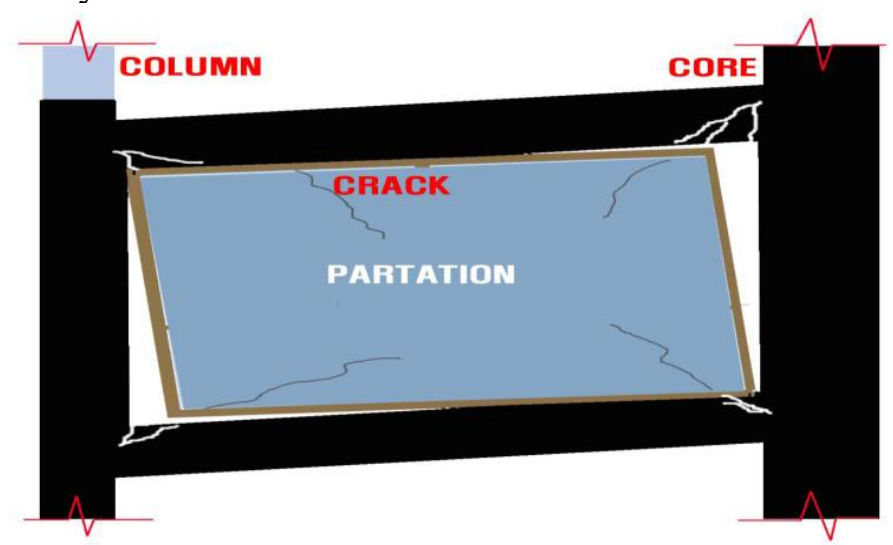

Figure 3: Examples for the effect of elastic column shortening.

\section{The Finite Element Model}

To observe the effects of nonlinear material property; creep, shrinkage and elastic shortening, over linear static analysis finite element models are formed using MIDAS GEN where construction simulation analysis is included along with linear static analysis. To meet this objective, all loads and sections are designed and applied at certain time according to proposed construction sequence. The time-dependent effects of creep, shrinkage, the variation of concrete stiffness with time, and sequential loading were accounted for in the threedimensional finite-element analysis model (Figure 4). Nonlinear properties for material, creep and shrinkage, were defined as per CEB-FIP code [2] (Figure 4). Construction analysis and loading were also defined according to Table 1.

Figure $4 \mathrm{a}$ shows the three dimensional finite element analysis models used for the construction staged analysis. A prototype building which comprise of a 50 story tower with total heights of $175.0 \mathrm{~m}$ is selected to perform the analysis. This building is modified from a real designed and constructed building to reflect a model for buildings with transfer floor.

In the current investigation, the location of the transfer floor is chosen at $20 \%$ of the total building height measured from the foundation and fixed throughout the investigation. The floor area is $20.0 \mathrm{~m}$ x $48.0 \mathrm{~m}$ where the spacing between the columns under the transfer floor is $8.0 \mathrm{~m}$ and while it is $4.0 \mathrm{~m}$ above the transfer floor. The typical story height is $3.5 \mathrm{~m}$. The transfer slab is $2000 \mathrm{~mm}$ thick solid plate supported on $1.4 \mathrm{~m} \mathrm{x} 1.4 \mathrm{~m}$ columns (underneath the slab) and supports $0.30 \mathrm{~m} \times 8.0 \mathrm{~m}$ shear walls above the slab. For all typical floors above the transfer floor level and at transfer floor, $3.0 \mathrm{kN} / \mathrm{m} 2$ superimposed dead load was considered. The live load was taken to be $2.0 \mathrm{kN} / \mathrm{m} 2$ at these floors. For all typical floors below the transfer floor, superimposed dead load and live loads were taken to be $4.5 \mathrm{kN} / \mathrm{m} 2$ and $5.0 \mathrm{kN} / \mathrm{m} 2$, respectively. Figure $4 \mathrm{~b}$ shows definition of nonlinear properties for material, creep, according to CEB-FIP code which is adopted in the numerical analysis and Figure 4c shows definition of shrinkage.

Table 1 and Figure 5 show the construction schedule adopted in the numerical model where the construction sequence is assumed as 3 levels of shoring and the construction cycle time for one floor is 7 days, which is considered as one stage in the construction analysis staging. The time considered for removal of lowest level of shores form and concreting of top floor is 5 days. Applying the super imposed dead loads starts at 351 days after the removal of all formwork for all floors and finalizing concerting of the last two floors; live loads are applied after finalizing the superimposed dead loads. 

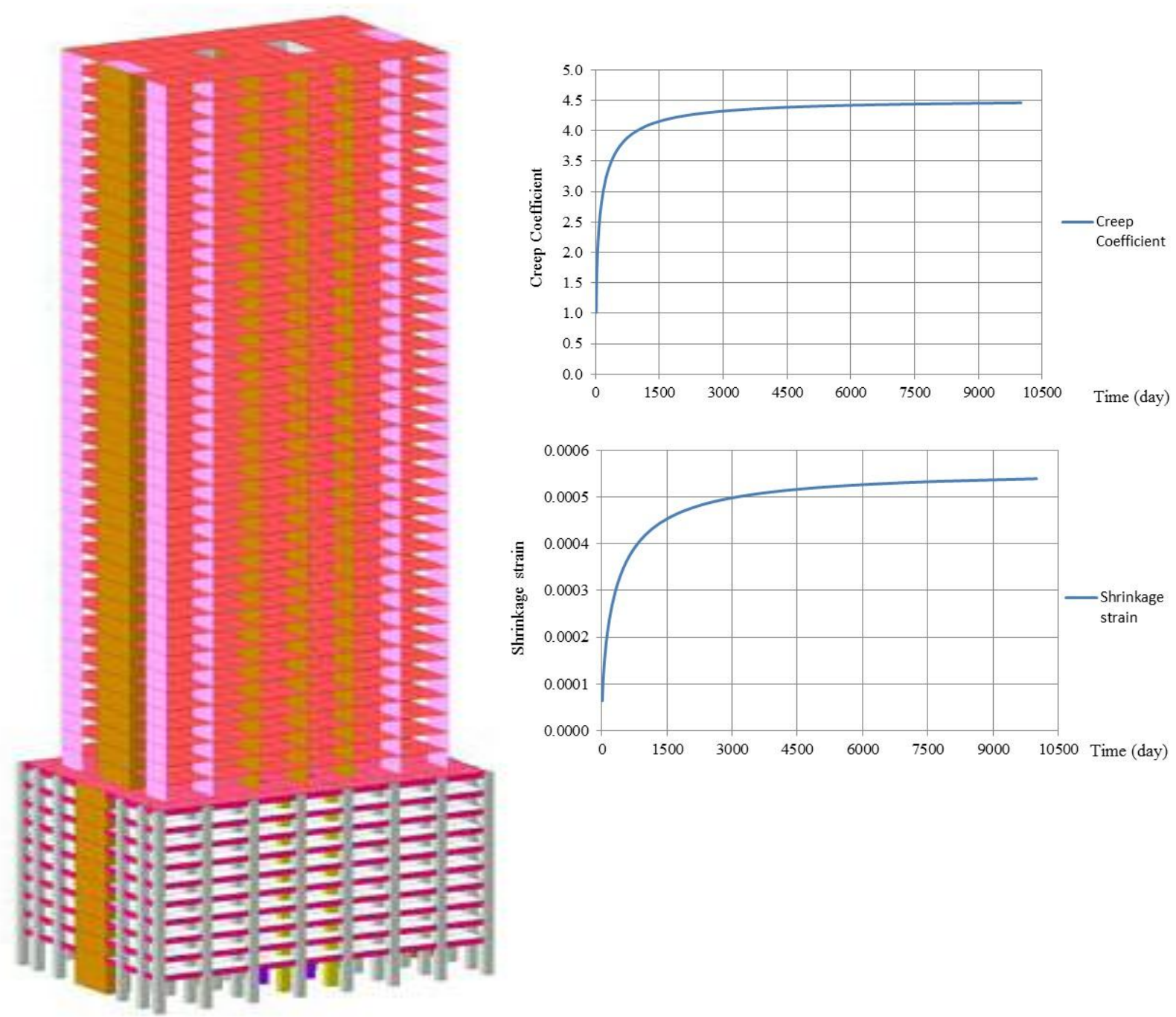

Figure 4: a) 3D Model of the building (left), b) Time-dependent creep model (top right) and c). Timedependent shrinkage model (bottom right)

Figure 5 shows the construction sequence for every construction staged analysis stage. It shows the set dates/time for the formwork installation then the casting dates for floors followed by the removal of formwork. This figure shows that the every floor requires 19 days for installation the formwork followed by casting then reaching to the removal of formwork.

\section{Response of the Prototype Building Model}

The global behavior of the building is presented as an indicator for the behavior of buildings with transfer floors considering the effect of construction stages.

\section{a. Forces}

This part will present the effect of considering the construction stages in analyzing high-rise buildings with transfer floors on the straining actions (axial forces, bending moments, and shear forces) in columns, beams and walls. 
Table 1.1: Construction schedule

\begin{tabular}{|c|c|c|c|c|c|c|c|}
\hline $\begin{array}{c}\text { Stage } \\
\text { time }\end{array}$ & $\begin{array}{l}\text { Prog } \\
\text { date }\end{array}$ & Stage & $\begin{array}{c}\text { Concrete } \\
\text { Casting }\end{array}$ & $\begin{array}{c}\text { Formwork } \\
\text { Installation }\end{array}$ & $\begin{array}{c}\text { Formwork } \\
\text { Removal } \\
\end{array}$ & Work & Date \\
\hline & & & & P01 & & P01 Formwork inst. & 1 \\
\hline & & & P01 & & & P01 Concrete casting & 3 \\
\hline & & & & P02 & & P02 Formwork inst. & 8 \\
\hline & & & P02 & & & P02 Concrete casting & 10 \\
\hline & & & & $\mathrm{P} 03$ & & P03 Formwork inst. & 15 \\
\hline & & & P03 & & & P03 Concrete casting & 17 \\
\hline \multirow[t]{3}{*}{7} & 330 & 46 & & & $\mathrm{~T} 38$ & $\begin{array}{l}\text { T38 Formwork Rem., } \\
\text { P01-P05 SDL }\end{array}$ & 351 \\
\hline & 333 & & & & & P06-TR SDL & 354 \\
\hline & 336 & & & & & P07-TR SDL & 357 \\
\hline \multirow[t]{3}{*}{7} & 337 & 47 & & & Roof & $\begin{array}{l}\text { Roof Formwork Rem., } \\
\text { T01-T03 SDL }\end{array}$ & 358 \\
\hline & 340 & & & & & T04-T06 SDL & 361 \\
\hline & 343 & & & & & T07-T10 SDL & 364 \\
\hline \multirow[t]{3}{*}{7} & 344 & 48 & & & & T11-T15 SDL & 365 \\
\hline & 347 & & & & & T16-T20 SDL & 368 \\
\hline & 350 & & & & & T21-T25 SDL & 371 \\
\hline \multirow[t]{3}{*}{7} & 351 & 49 & & & & T26-T30 SDL & 372 \\
\hline & 354 & & & & & T31-T35 SDL & 375 \\
\hline & 357 & & & & & T36-Roof SDL & 378 \\
\hline 28 & 385 & dummy & & & & Live Load & 406 \\
\hline
\end{tabular}
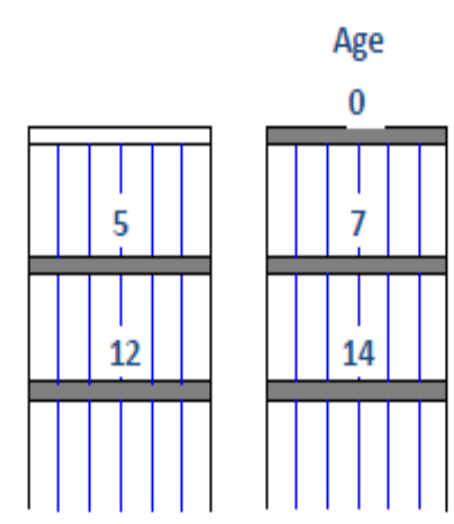

3F Formwork
Installation

15th day

\begin{abstract}
3F Concrete
Casting
\end{abstract}

17th day

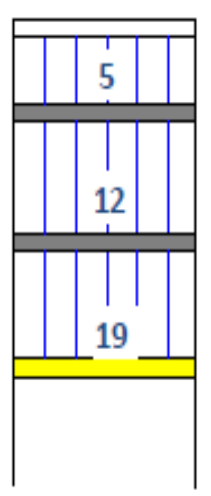
1F Formwork
Removal 4F Formwork Installation

22th day
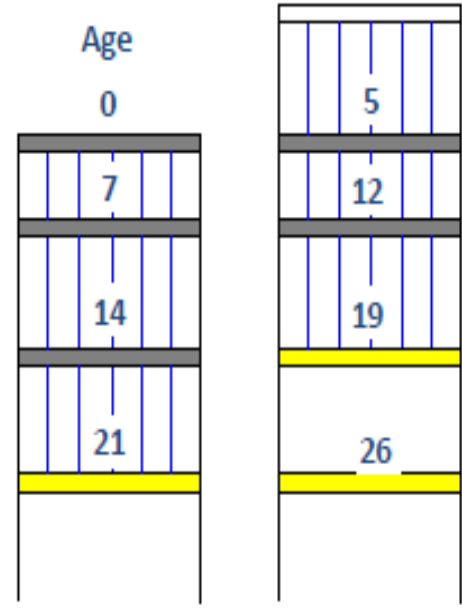

2F Formwork

Removal 5F Formwork Installation

29th day

Figure 5: Construction schedule sequence used for staged construction analysis [1]. 
Figure 6 shows axial forces in columns of building below the transfer floor slabs for the two load cases: total loads considering and neglecting the effect of construction stages, respectively. The figures show that time-dependent factors (creep and shrinkage) increase the values of the axial forces in columns by about 5\% compared to those obtained from conventional analysis (neglecting construction stage analysis/material time dependent effect).

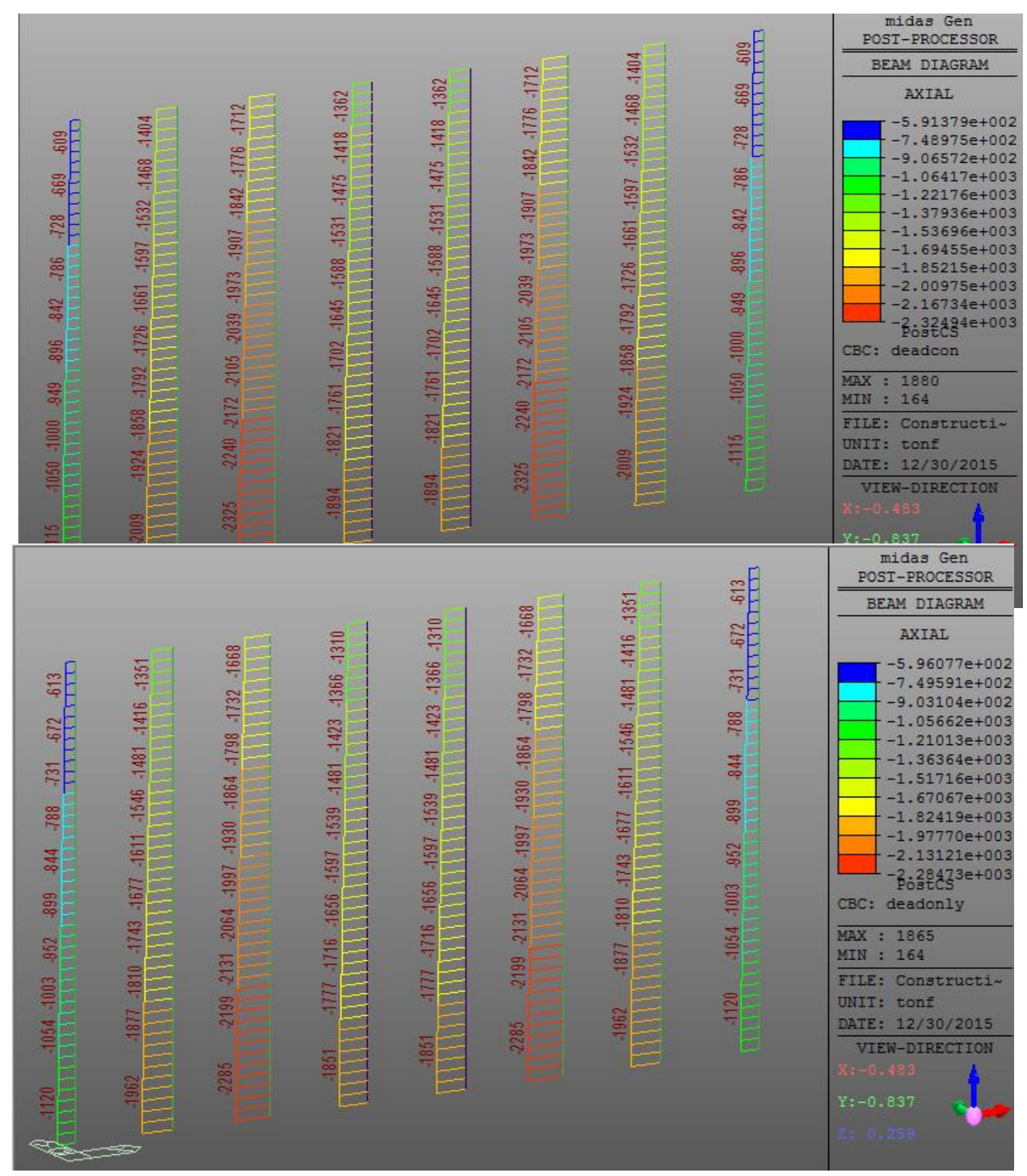

Figures 6: Axial forces distribution in columns due to total load considering the constuction stages in the analysis (above) and neglecting it (below).

Figures 7 shows that construction stage analysis leads to a small redistribution of the bending moments in columns. The bending moment redistribution resulting from construction stage analysis changes by about 5\% compared to that resulting from conventional analysis (neglecting construction stage analysis/material time dependent effect). 

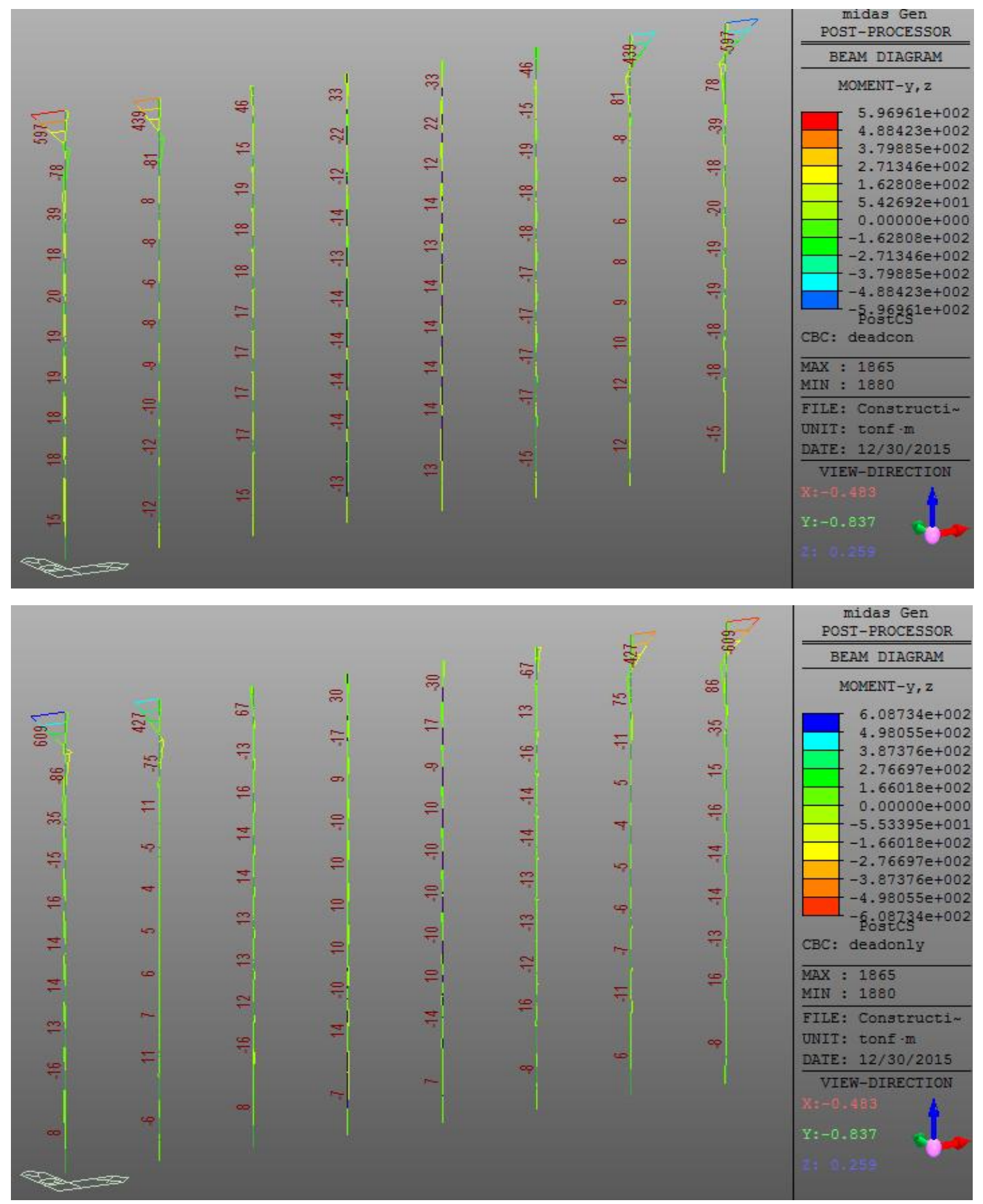

Figure 7: Bending moment distribution in columns due to dead loads considering the constuction stages in the analysis (above) and neglecting it (below).

Figure 8 shows axial forces in walls planted above transfer floor slab considering and neglecting the effect of construction stage analysis, respectively. The figure shows that time dependent factors (creep and shrinkage) increase the values of axial forces in walls by about $10-15 \%$ compared to that obtained from conventional analysis (neglecting construction stages/material time dependent effect). 

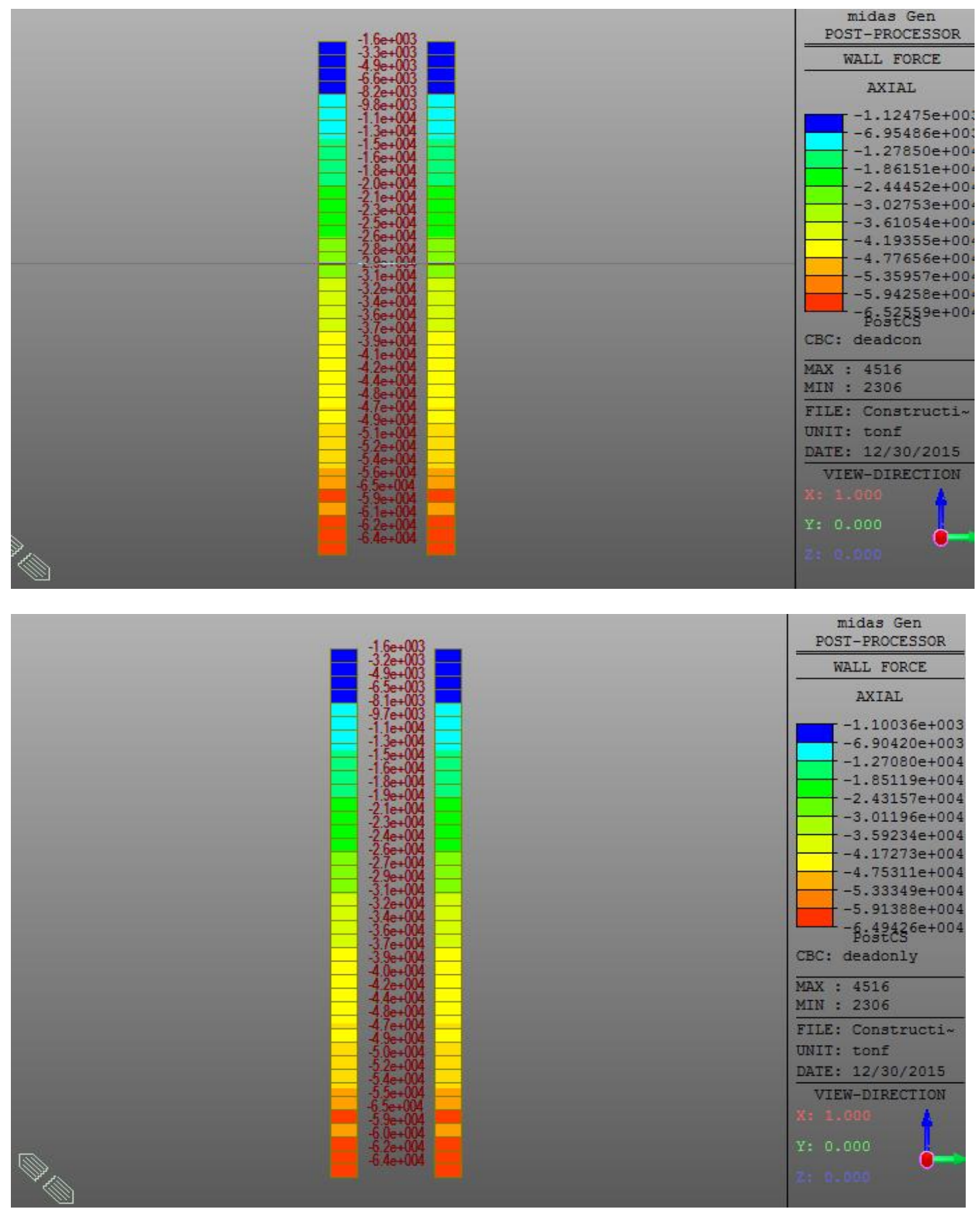

Figure 8: Axial force distribution in R.C. walls above transfer slabs due to dead loads considering the constuction stages in the analysis (above) and neglecting it (below).

As for the bending moment in planted walls, Figure 9 shows that construction stage analysis leads to a redistribution of the bending moments in the walls. The redistribution due to the construction stages changes the values of the bending moment by about 30-40\% compared to these resulting from the conventional analysis. However, it is noted that design of these walls under the factored loads combinations as per ASCE 07-10 [7] is safe in both cases: considering and neglecting construction stage analysis. 

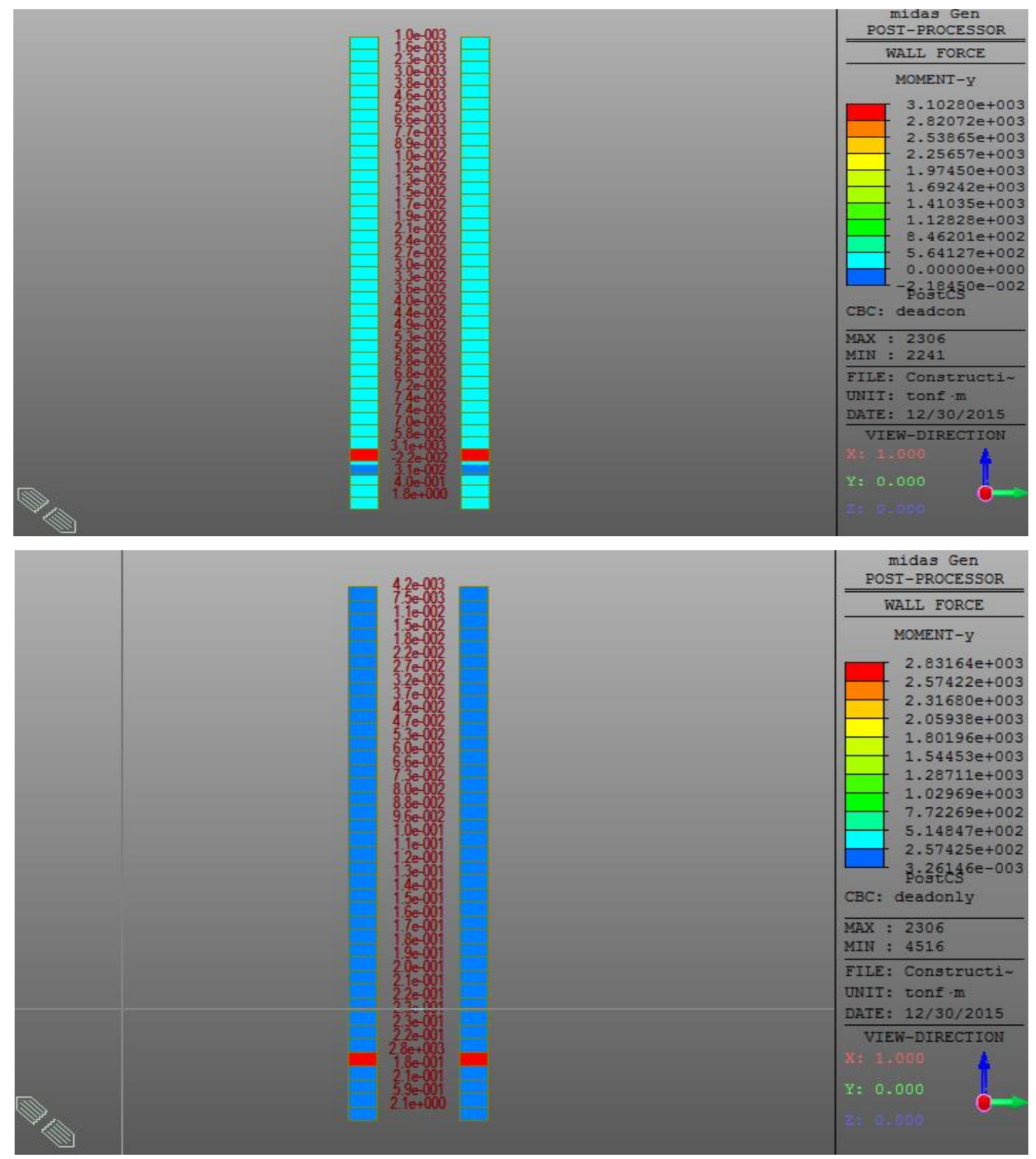

Figure 9: Bending moment distribution in R.C. walls above transfer slabs due to dead loads considering the constuction stages in the analysis (above) and neglecting it (below).

\section{b. Displacement}

The effect of considering construction stages in analyzing high-rise buildings with transfer floors on the horizontal displacement of all stories is presented. Figure 10 shows the story displacement distribution along the building height for load combination of total loads, as per design codes. Displacement is investigated in the horizontal X-direction considering seismic, dead, and live loads. The only different between the two cases of considering and neglecting construction analysis is the effect of dead loads. It can be concluded that values of the horizontal displacement are the same for both cases of analysis. The construction stage analysis affects the distribution of the internal forces but it has no effect on the overall lateral displacement of the building. 


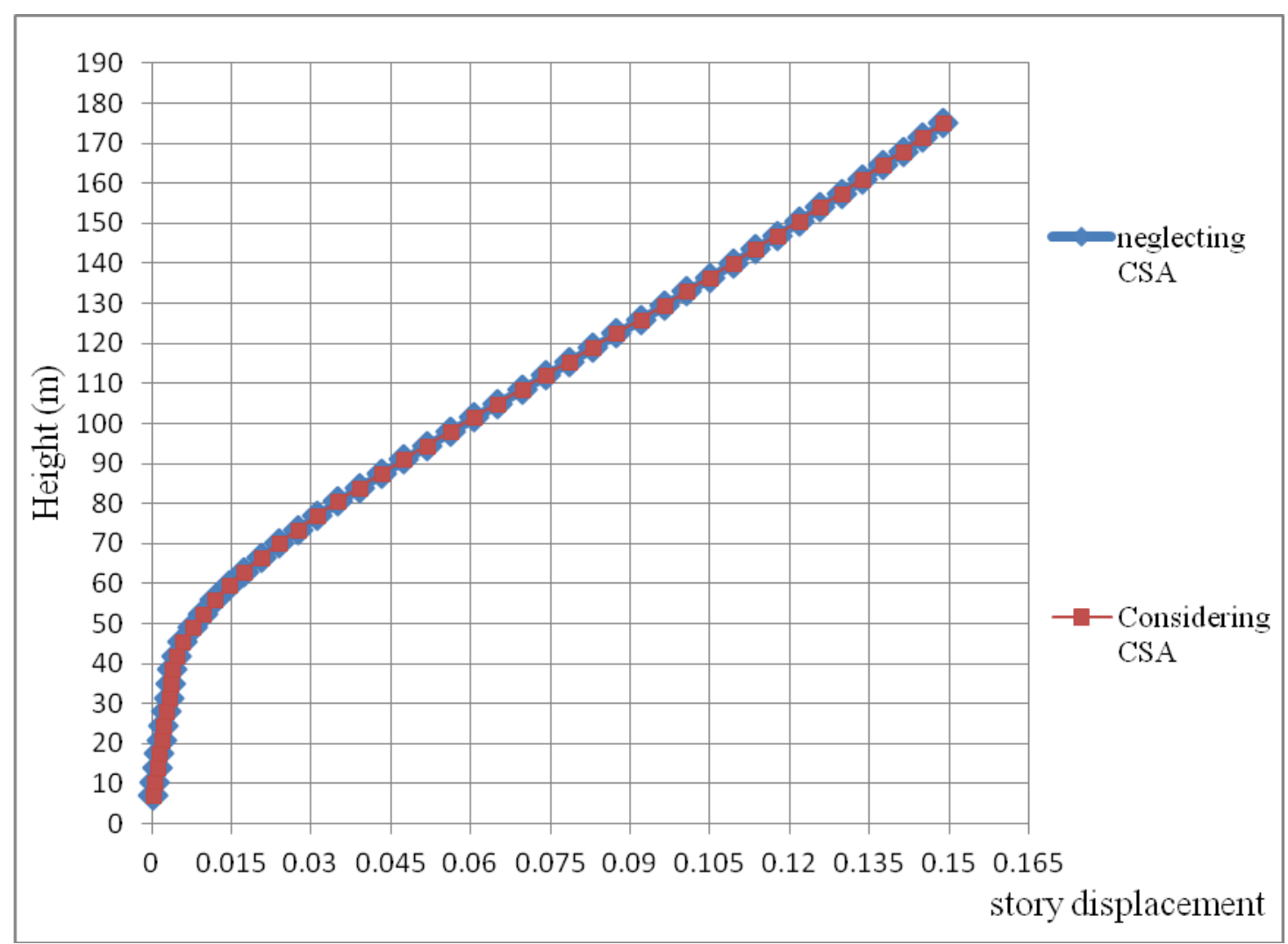

Figure 10: Story displacement considering and neglecting construction analysis.

\section{c. Elastic Column Shortening}

In this part results for elastic column shortening are presented to explain the behavior of high rise buildings with transfer slabs when staged construction analysis is considered. Figure 11 shows the locations chosen for structure elements (columns and walls) at the transfer floor level that are used in studying elastic shortening and the effect of transfer slabs deformations on these values. Several elements are chosen for this study: columns within the footprint of planted tower with different types, internal and external ones, corner and exterior columns outside the tower footprint are presented in addition to chosen RC cores and shear walls.

Figure 12 shows the vertical displacement values for Column $1(1.70 \times 1.70 \mathrm{~m})$ along the building height due to of creep, shrinkage, elastic shortening, and total loads. It can be concluded that values of vertical displacement due to creep is the largest values compared to values due to shrinkage or elastic shortening. Behavior of the building due to creep and elastic shortening is similar to its behavior due to total loads. On the other hand, the behavior of the building due to shrinkage is similar to a free cantilever behavior. Values of the displacement due to shrinkage are about $18 \%$ of the displacement due to total loads. Wherein the same time, displacement due to elastic shortening and creep is about $32 \%$ and $55 \%$, respectively of that due to total load. The most effective time dependent effect is the one due to creep. In general, elastic shortening should, thus, be considered in analysis of high-rise buildings. 


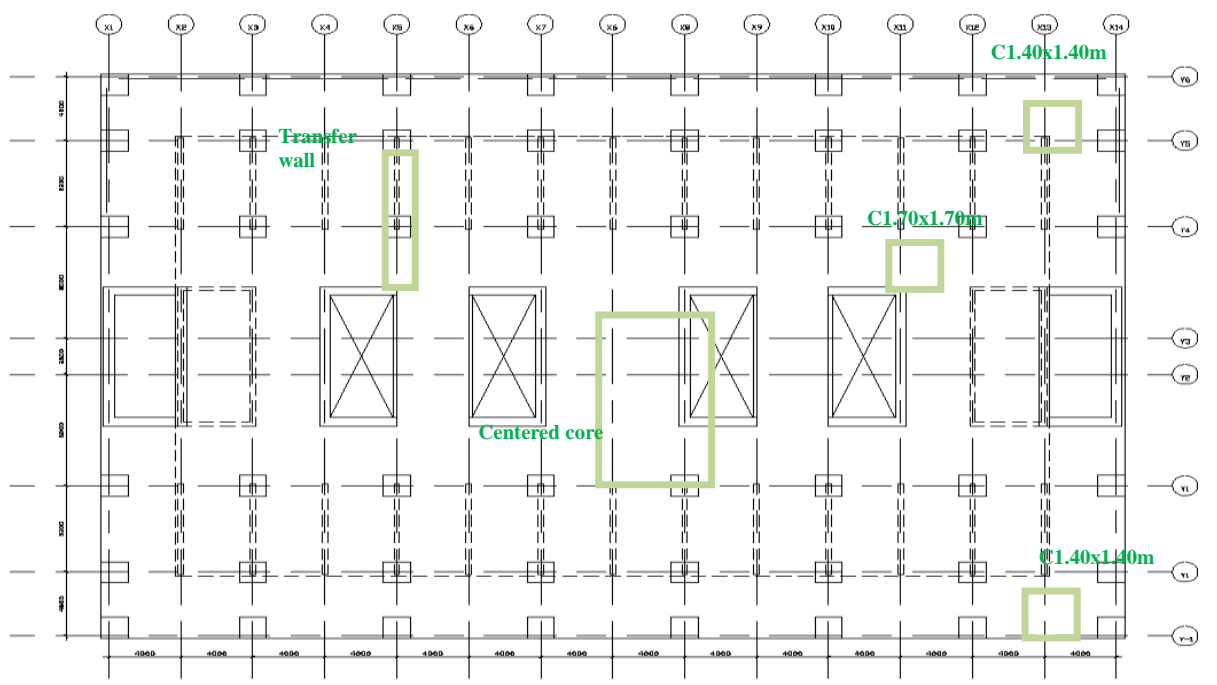

Fig. 11: Locations of vertical elements chosen for elastic shortening study

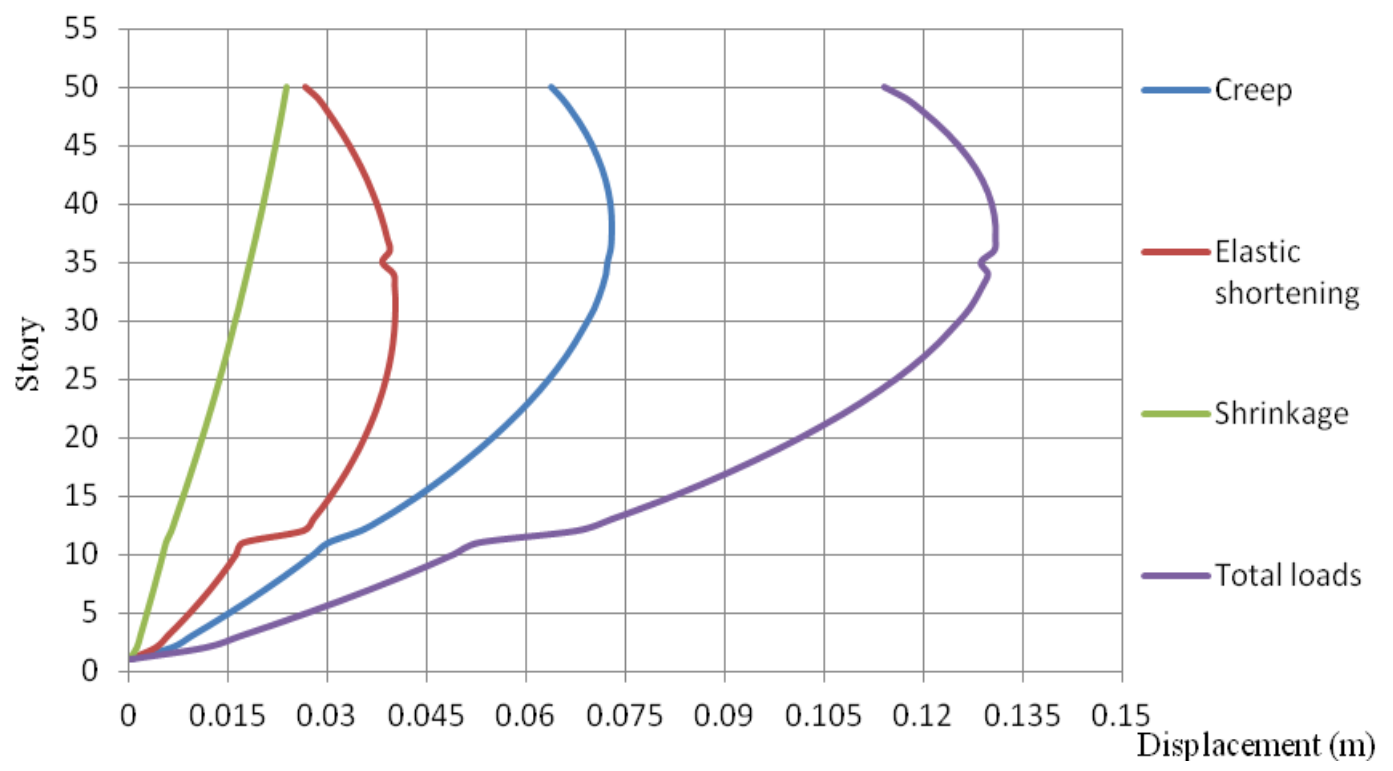

Fig. 12: Displacements for column $1.70 X 1.70 \mathrm{~m}$ within the tower area.

Figures 13 and 14 show elastic shortening values for corner and exterior columns $(1.40 \times 1.40 \mathrm{~m})$ outside the high-rise building area due to creep, shrinkage, elastic shortening and total loads. It can be concluded that values of displacement due to creep are the largest. Values of displacement due to shrinkage are about $20 \%$ of the displacements due to total loads, where values of displacement due to elastic shortening and creep are about $35 \%$ and $50 \%$, respectively of those due to total loads.

Figure 15 shows that elastic shortening values for the center core; starting from basement up to roof floor due to cases of creep, shrinkage, elastic shortening and total loads. Displacements due to creep are the largest values. Behavior of building due to creep and elastic shortening is similar to that of the overall displacement of building due to total loads, while behavior of building due to shrinkage is similar to that of a cantilever. Values of displacement due to shrinkage are $20 \%$ of those due to total loads where value of displacement due to elastic shortening and creep is $30 \%$ and $60 \%$, respectively. 


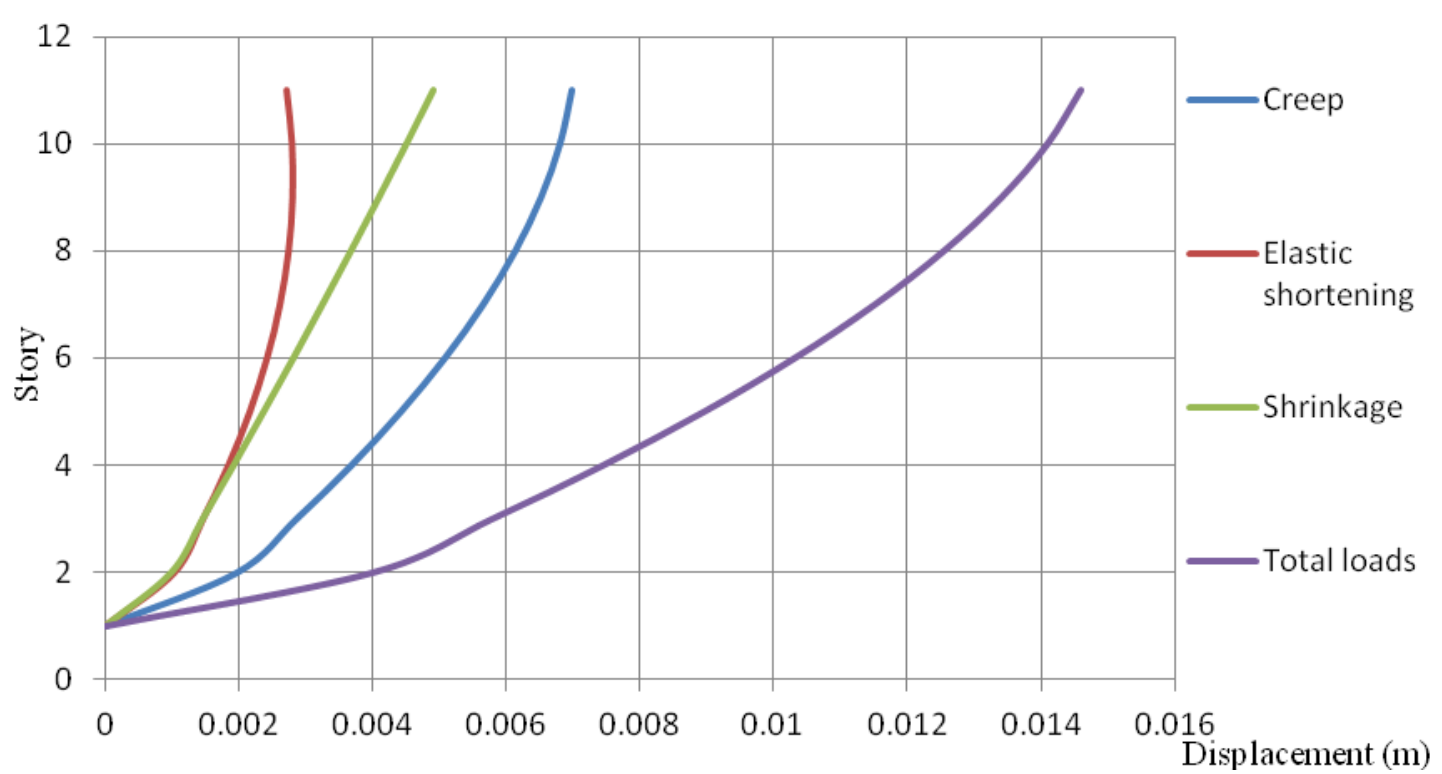

Figure 13: Displacements for corner columns 1.40X1.40 m outside Tower area.

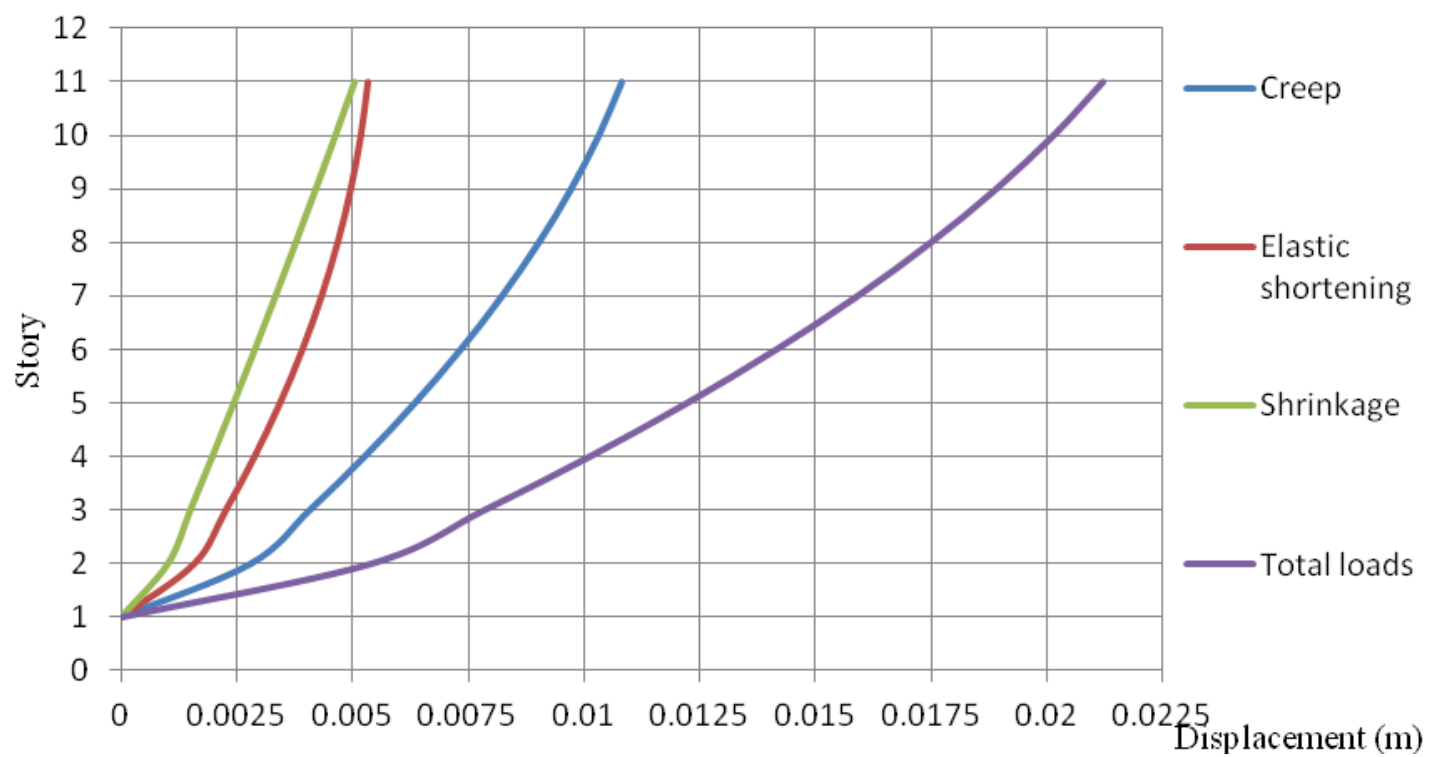

Figure 14: Displacements for exterior columns 1.40X1.40 m outside tower area.

Figure 16 shows that elastic shortening values for exterior transfer walls; starting from transfer floor up to roof. Displacements are due to cases of creep, shrinkage, elastic shortening and total loads. It can be concluded that displacements started from planting floor; transfer floor, but with values of displacement at transfer floor which is contrary to the concept of considering the transfer floor as a base for the above floors or separating the buildings to two parts in analysis. As such, high rise buildings with transfer floor should be studied as one unit without any separation to accurately study the effect of each part; below and above transfer floor. Displacement due to creep is the largest values among creep, shrinkage and elastic shortening. Behavior of building due to creep and elastic shortening is similar to overall displacement of building due to total loads, while behavior of building due to shrinkage is smooth cantilever action. Values of displacement due to shrinkage are $20 \%$ of displacements due to total loads where values of displacement due to elastic shortening and creep are $30 \%$ and $60 \%$, respectively. 


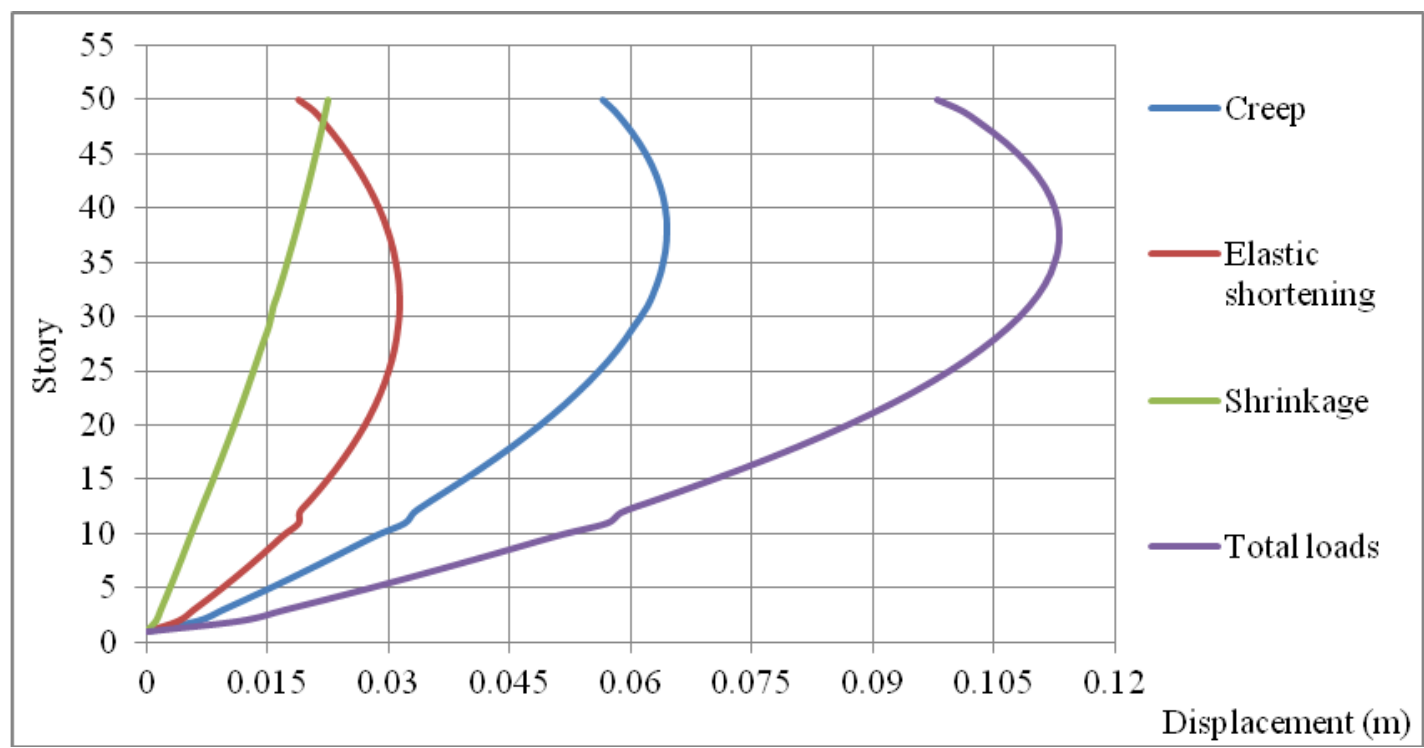

Figure 15: Displacements for centered core all over its height.

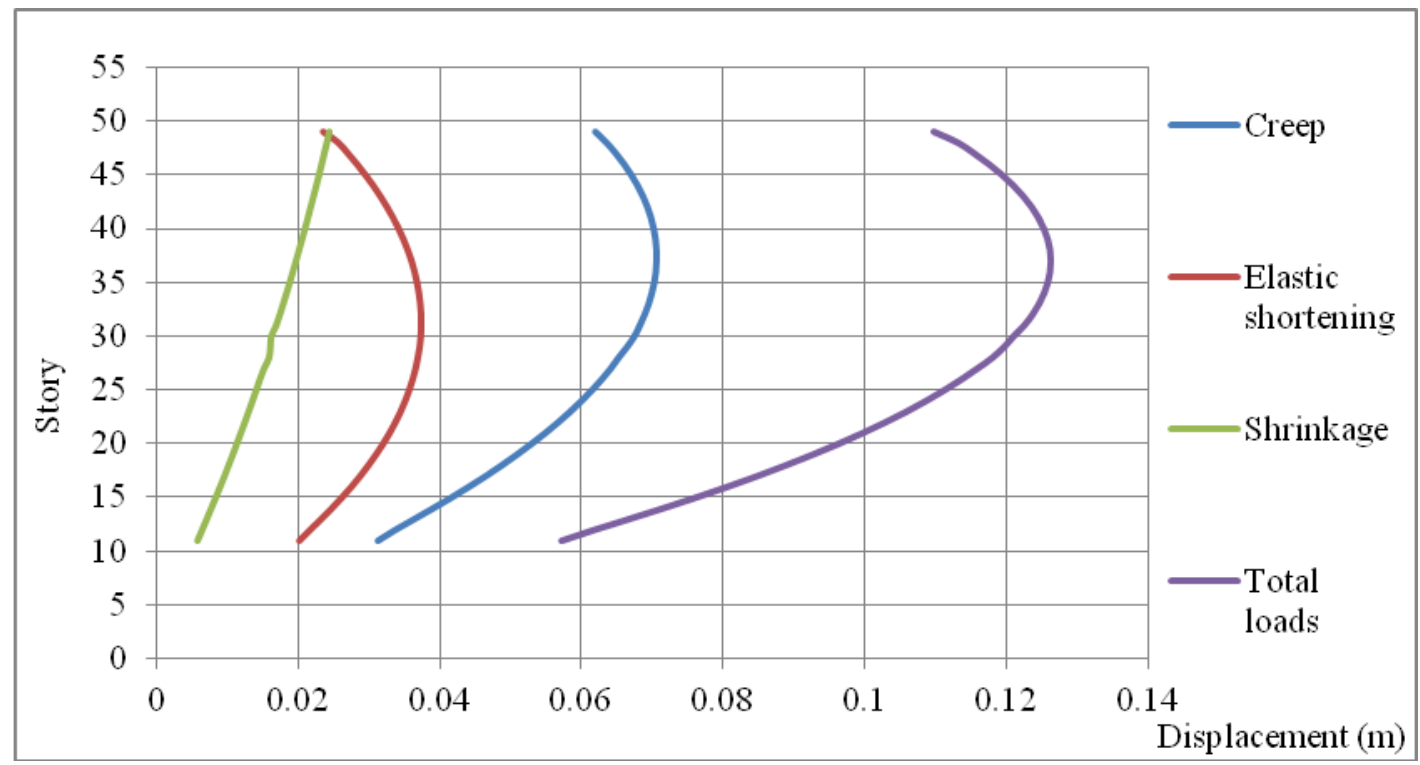

Figure 16: Displacements for exterior transfer walls above transfer floor.

\section{CONCLUSION}

Numerical analyses for a prototype building with a transfer floor have been performed. The effects of time dependent material properties on the overall behavior; forces and displacements, of high-rise buildings and consequently on the design process of these buildings were investigated in this research. The investigation was done through performing construction staged analysis and elastic shortening of columns.

Conclusions can be summarized as follow:

a. Construction stage analysis proved that $45 \%$ of the total loads are due to time dependent effect which leads to the importance of considering creep and shrinkage effect in structural analysis especially for high rise buildings.

b. Values of displacement due to shrinkage are $6 \%$ of total loads displacements where elastic shortening and creep effect are $30 \%$ and $65 \%$, respectively.

c. The displacement due to creep are more than values for shrinkage and elastic shortening.

d. Construction stage analysis affects the values and distribution of internal forces. As such, values of straining actions due to time dependent factors can govern the design and need to be checked. 
e. The increase in dead loads due to construction staged analysis is found to be within the $20 \%$ safety factor of the dead loads ultimate factors $(1.20 \mathrm{D}+\ldots)$ as per codes of practice.

f. It is found that displacement distribution is the same whether construction stage analysis is considered or not.

\section{Acknowledgment}

This work was done under the auspices of Dar Al-Handasah, Shair and Partners. The authors would like to acknowledge this in terms of providing all necessary hardware and/or software to perform this research. This is done as a part of DAR Al-Handasah research vision and professional development activities which aim at enhancing the technical ability of Dar's engineers and globally improving and augmenting the engineering knowledge.

\section{References}

[1] MIDAS Gen Package, MIDAS software Engineering Manual: Integrated Solution System for Building and General Structures; available from the URL: http://en.midasuser.com/product/gen_overview.asp

[2] CEB-FIP 90, international recommendation for the design and construction of concrete structures, Paris, London, 1990.

[3] Kang S., Choi J., Kim H. Kim I., "Prediction and compensation of column shortening for Bitexco financial tower", CTBUH conference, Seoul, P. 811-818, 2011.

[4] Dinar Y., Rasel M., Chowdhury M., "Chronological Construction Sequence Effects on Reinforced Concrete and Steel Buildings", the International Journal of Engineering and Science (IJES), Volume 3, issue 1, P. 52-63, 2014.

[5] Vafai. A., Ghadbian M.,Estekanchi H., Desai C., "Calculation of creep and shrinkage in tall concrete buildings using nonlinear stages construction analysis", Asian Journal of Civil Engineering (building and housing), Volume 10, No. 4, P. 409-426, 2009.

[6] Poojara D.S., Patal V.P., "Axial deformation of columns in multi-story R.C. buildings", International Journal of Civil Engineering and Technology (IJCIET), Volume 5, issue 3, P. 294-300, 2014.

[7] ASCE standards ASCE/SEI 7-10: American Society for Civil Engineers "Minimum design loads for buildings and other structures".

[8] Abdelbasset Y.A., Sayed-Ahmed E.Y., Mourad S.A. "performance of high rise buildings with transfer floors under seismic load ", PHD thesis (under preparation), Cairo university, Faculty of Engineering, 2016. 